\title{
Controlling Inbreeding by Constraining the Average Relationship Between Parents of Young Bulls Entering Al Progeny Test Programs
}

\author{
K. A. Weigel*and S. W. Lin† \\ *Department of Dairy Science \\ University of Wisconsin, Madison 53706 \\ †Department of Industrial Engineering \\ University of Wisconsin, Madison 53706
}

\begin{abstract}
Inbreeding is known to impair the health, fertility, and productivity of dairy cattle and other livestock species. Mating programs can address inbreeding concerns on the farm, at least in the short term, but long-term control of inbreeding in a dairy population requires consideration of relationships between young bulls entering AI progeny test programs. The present study discusses an application of optimal contribution methodology to selection of young AI bulls in the five major US dairy breeds. Elite cows and active AI sires from the Ayrshire, Brown Swiss, Guernsey, Holstein, and Jersey breeds were considered as potential bull parents. Genetic merit of selected sires and dams was maximized subject to various constraints on the mean additive genetic relationship within the selected group. Relationships between selected parents can be reduced substantially relative to current levels, but the corresponding reduction in genetic merit may be large. This loss in genetic merit occurs due to lower selection intensity, although it is mainly a reflection of a larger number of bull parents (with progeny more evenly distributed among these parents), rather than selection of genetically inferior "outcross" parents that wouldn't otherwise have been considered. Selected parents were generally older and slightly less inbred than those that would have been chosen had inbreeding been ignored. Although severe restrictions on relationships can be costly, in terms of lost genetic progress, it appears that moderate constraints can keep relationships at a manageable level without a significant loss in genetic merit. Cooperation between breed associations and several competing AI companies may be required to facilitate implementation of this methodology in dispersed populations, but if this can be accomplished, prospects for
\end{abstract}

Received November 27, 2001.

Accepted March 2, 2002.

Corresponding author: K. A. Weigel; e-mail: weigel@calshp. cals.wisc.edu. achieving a balance between inbreeding and selection seem positive.

(Key words: inbreeding, dairy cattle, progeny testing)

\section{INTRODUCTION}

Inbreeding is a growing concern in livestock breeding programs. Advances in statistical methods for breeding value estimation, such as animal model BLUP, have increased the accuracy of sire and cow PTA, but the probability of coselection of related animals has also increased. Similarly, advances in reproductive technology, such as AI and embryo transfer have increased the reproductive capacity of individual sires and dams. Inbreeding depression can reduce farm profitability via reductions in the health, fertility, and performance of inbred animals relative to their contemporaries. Smith et al. (1998) reported that a $1 \%$ increase in inbreeding of US Holstein cows led to decreases of $37 \mathrm{~kg}$ of milk, 1.2 $\mathrm{kg}$ of fat, and $1.2 \mathrm{~kg}$ of protein per lactation, increases of $0.4 \mathrm{~d}$ in age at first calving and $0.3 \mathrm{~d}$ in calving interval, and a decrease of $13.1 \mathrm{~d}$ in length of productive life. Furthermore, Wilk and McDaniel (1995) noted that offspring of Danish Jersey sires and US Jersey dams had a $12.4 \%$ higher rate of survival to first calving than offspring of US Jersey sires and US Jersey dams in the same experimental herd. This advantage was attributed to a reduction of inbreeding depression in the former group.

A comprehensive review of methods to control inbreeding in livestock breeding programs was given by Weigel (2001). Numerous strategies were considered, including restricting family size, creating sublines, modifying BLUP evaluations, using computerized mating programs, and applying optimal contribution theory. The latter two alternatives appear most promising for short-term control of inbreeding on the farm and long-term control of inbreeding in the population, respectively. Weigel and Lin (2000) showed that a welldesigned computerized sire selection and mating program could reduce inbreeding levels in the next generation of replacement heifers by $1.8 \%$ in Holsteins and 
$2.8 \%$ in Jerseys. Corresponding increases in lifetime net income per animal were $\$ 37$ and $\$ 60$ in Holsteins and Jerseys, respectively. The authors noted that, although mate selection programs can help control inbreeding in the next generation, such programs offer little benefit with respect to long-term maintenance of genetic variation in the population. Mating programs simply make the best available use of the AI sires that are currently available, and if there is little genetic diversity present among these sires, mating programs will be less effective. Because AI plays such an important role in dairy cattle breeding programs, success in controlling inbreeding over the long term will depend on our ability to limit genetic relationships between young bulls in AI progeny test programs.

Several authors, including Woolliams and Meuwissen (1993), Wray and Goddard (1994), Brisbane and Gibson (1995), Meuwissen and Goddard (1997), and Meuwissen (1997) have suggested strategies in which genetic merit of the selected group is maximized subject to a constraint or penalty on the average relationship within the selected group. In this manner, the potential contribution of each animal to the genetic merit of the selected group and to the average relationship within the selected group is determined, and animals that make an "optimal contribution" to future generations are chosen. The present paper follows the approach of Meuwissen (1997), in which average genetic merit of the selected group, $\mathbf{c}^{\prime} \mathbf{u}$, is maximized, subject to a constraint on the average relationship within this group, $\mathbf{c}^{\prime} \mathbf{A} \mathbf{c} \leq(\mathrm{R}+2 \Delta \mathrm{F})$, where $\mathbf{c}$ is a vector of optimum contributions of each selection candidate, $\mathbf{u}$ is a vector of EBV of selection candidates, $\mathbf{A}$ is a relationship matrix between selection candidates, $R$ is the mean additive genetic relationship in the current generation, and $\Delta \mathrm{F}$ is the acceptable (predefined) rate of increase in inbreeding. Additional constraints can be placed on the reproductive capacity of male or female selection candidates. These authors showed via simulation that this method could achieve genetic gains 21 to $60 \%$ greater than selection on BLUP EBV after responses were standardized to a constant level of inbreeding. Later studies by Grundy et al. (1998), Meuwissen and Sonesson (1998), Grundy et al. (2000), and Sonesson et al. (2000) have considered modifications of the method of Meuwissen (1997) to accommodate overlapping generations.

The objective of the present study was to apply the optimal contribution procedure of Meuwissen (1997) to selection of young AI sires in the five major US dairy breeds. Of particular interest were parameters of the selected group of bull parents (according to the specified level of inbreeding), such as the number of sires and dams, and their average age, inbreeding coefficient, and genetic merit.

\section{MATERIALS AND METHODS}

\section{Data}

Data for the present study were provided by the USDA Animal Improvement Programs Laboratory. These data consisted of Lifetime Net Merit PTA of elite (top 1\% of) cows in the Ayrshire, Brown Swiss, Guernsey, Holstein, and Jersey breeds in February 2001, as well as the active AI sires in each of these breeds. Because of computational limitations, data for the Holstein breed were limited to the top $25 \%$ of active AI bulls, according to Lifetime Net Merit, and a random sample of $20 \%$ of the elite cows. Pedigrees were traced back to 1960 for all selection candidates. Holstein and Jersey animals were required to have at least four generations of known parentage, while three generations were required for the Ayrshire, Brown Swiss, and Guernsey breeds.

\section{Methodology}

For each breed, the relationship matrix, $\mathbf{A}$, between all selection candidates (i.e., elite cows and active AI sires) was calculated. Similarly, a vector of estimated breeding values, $\mathbf{u}$, was constructed for each breed; this vector contained the Lifetime Net Merit PTA of each selection candidate. Average genetic merit, $\mathbf{c}^{\prime} \mathbf{u}$, of the selected group was maximized, subject to the constraint $\mathbf{c}^{\prime} \mathbf{A c} \leq \mathrm{x}$, where the average additive genetic relationship in the selected group, $\mathrm{x}$, was varied from $8,10,12$, . . , 26\%. In this analysis, we assumed that genetic relationships among selected parents in the current generation $(8,10,12, \ldots, 26 \%)$ will correspond approximately to inbreeding levels of $4,5,6, \ldots, 13 \%$ in the next generation. The highest level of inbreeding (13\%) could be thought of as an experimental control, because there was essentially no attempt to control inbreeding in this case. The optimal contribution vector, c, contains the proportion offspring (young bulls) that should be provided by each sire or dam. The number of young bulls required in the Ayrshire, Brown Swiss, Guernsey, Holstein, and Jersey breeds was assumed to be 15, 25, 20,1300, and 135, respectively (approximately the number of AI young sires of each breed tested annually in the United States). Initially, the reproductive capacities of males and females were left unconstrained. In a subsequent analysis, the reproductive capacity of females was constrained such that each dam could have no more than five progeny.

Several attributes of the optimal contribution vector, c, were examined, including the number of sires and dams, their inbreeding coefficients, the expected inbreeding coefficients of their future progeny (sires only), and their average Lifetime Net Merit before and after 
Table 1. Summary of the data used in the present study.

\begin{tabular}{|c|c|c|c|c|c|c|c|c|c|c|}
\hline \multirow[b]{2}{*}{ Breed } & \multirow{2}{*}{$\begin{array}{l}\text { Young bulls } \\
\text { Needed }\end{array}$} & \multicolumn{4}{|c|}{ Elite cows } & \multicolumn{4}{|c|}{ Active AI bulls } & \multirow{2}{*}{$\begin{array}{l}\text { M-F } \\
\text { Rel. }^{3}\end{array}$} \\
\hline & & No. & Net merit & $\mathrm{F}^{1}$ & $\operatorname{Rel}^{2}$ & No. & Net merit & $\mathrm{F}$ & Rel. & \\
\hline Ayrshire & 15 & 162 & $\$ 352$ & 4.6 & 12.8 & 20 & $\$ 222$ & 4.1 & 12.1 & 12.8 \\
\hline Brown Swiss & 25 & 350 & $\$ 461$ & 3.5 & 11.8 & 48 & $\$ 302$ & 2.6 & 13.2 & 12.2 \\
\hline Guernsey & 20 & 207 & $\$ 349$ & 3.8 & 12.7 & 19 & $\$ 280$ & 3.2 & 12.2 & 12.2 \\
\hline Holstein & 1300 & 1433 & $\$ 477$ & 4.2 & 10.6 & 141 & $\$ 457$ & 4.4 & 11.5 & 10.9 \\
\hline Jersey & 135 & 1139 & $\$ 421$ & 4.8 & 16.3 & 90 & $\$ 289$ & 4.4 & 17.1 & 16.4 \\
\hline
\end{tabular}

adjusting to zero inbreeding (using a penalty of $\$ 23$ in lifetime net income per $1 \%$ inbreeding). All means were weighted according to the suggested proportion of progeny from each sire or dam (i.e., the corresponding element of the optimal contribution vector, $\mathbf{c}$ ).

\section{RESULTS AND DISCUSSION}

A summary of the selection candidates is shown in Table 1 . The number of potential bull dams ranged from 162 Ayrshires to 1433 Holsteins, while the number of potential bull sires ranged from 19 Guernseys to 141 Holsteins. The mean inbreeding coefficient of elite Brown Swiss cows was lowest at 3.5\% and the inbreeding coefficient of elite Jersey cows was highest at $4.8 \%$. The mean inbreeding coefficient of Brown Swiss AI sires was lowest at $2.6 \%$, while the corresponding parameters for Holstein and Jersey AI sires were highest at $4.4 \%$. The mean relationship between elite cows ranged from $10.6 \%$ for Holsteins to $16.3 \%$ for Jerseys, while the mean relationship between active AI sires ranged from $11.5 \%$ for Holsteins to $17.1 \%$ for Jerseys. The mean relationship between elite cows and active AI sires ranged from $10.9 \%$ in Holsteins to $16.4 \%$ in Jerseys.

The optimal number of bull sires at each level of the inbreeding constraint is shown in Table 2. The lowest achievable levels of inbreeding in the next generation were 6\% for Ayrshires and Guernseys, 5\% for Brown Swiss, and $4 \%$ for Holsteins and Jerseys. The optimal number of bull sires at the minimum inbreeding constraint ranged from 15 for Ayrshires to 55 (58) for Holsteins without (with) a constraint of five progeny per bull dam. At the maximum inbreeding constraint (13\%), on the other hand, the optimal number of bull sires ranged from 2 in the Guernsey breed (with a constraint of the female reproductive rate) to 10 in the Brown Swiss breed (without the reproductive constraint). In general, the optimal number of bull sires decreased rapidly as the inbreeding constraint increased, particularly at low levels of inbreeding. The optimal number of bull sires was typically lower when the female reproductive rate was constrained, because more bull dams were chosen. However, the reproductive constraint had little effect on the number of sires and dams chosen in the numerically small breeds, because relatively few young sires (and hence few bull dams) were needed. The optimal number of bull dams at each level of the inbreeding constraint is shown in Table 3. This number varied widely, from three Holstein bull dams at $13 \%$ inbreeding (without a reproductive constraint), to 289 Holstein bull dams at $4 \%$ inbreeding (with a reproductive constraint). As expected, the optimal number of

Table 2. Optimal number of bull sires, according to the level of inbreeding constraint, with $(R)$ and without (U) a restriction of five progeny per dam.

\begin{tabular}{|c|c|c|c|c|c|c|c|c|c|c|}
\hline \multirow{2}{*}{$\begin{array}{l}\text { Inbreeding } \\
\text { constraint } \\
(\%)\end{array}$} & \multicolumn{2}{|c|}{ Ayrshire } & \multicolumn{2}{|c|}{ Brown Swiss } & \multicolumn{2}{|c|}{ Guernsey } & \multicolumn{2}{|c|}{ Holstein } & \multicolumn{2}{|c|}{ Jersey } \\
\hline & $\mathrm{U}$ & $\mathrm{R}$ & $\mathrm{U}$ & $\mathrm{R}$ & $\mathrm{U}$ & $\mathrm{R}$ & $\mathrm{U}$ & $\mathrm{R}$ & $\mathrm{U}$ & $\mathrm{R}$ \\
\hline 4 & & & & & & & 55 & 58 & 28 & 28 \\
\hline 5 & & & 23 & 23 & & & 47 & 36 & 20 & 21 \\
\hline 6 & 15 & 15 & 19 & 19 & 15 & 15 & 35 & 34 & 15 & 15 \\
\hline 7 & 12 & 12 & 15 & 14 & 12 & 12 & 18 & 7 & 14 & 14 \\
\hline 8 & 8 & 8 & 14 & 13 & 9 & 9 & 11 & 6 & 13 & 12 \\
\hline 9 & 7 & 7 & 12 & 10 & 8 & 7 & 10 & 5 & 13 & 9 \\
\hline 10 & 5 & 5 & 11 & 9 & 6 & 6 & 7 & 3 & 11 & 9 \\
\hline 11 & 4 & 4 & 11 & 8 & 5 & 4 & 7 & 3 & 10 & 5 \\
\hline 12 & 4 & 4 & 10 & 5 & 4 & 3 & 6 & 3 & 10 & 4 \\
\hline 13 & 4 & 4 & 10 & 3 & 4 & 2 & 6 & 3 & 9 & 4 \\
\hline
\end{tabular}


Table 3. Optimal number of bull dams, according to the level of inbreeding constraint, with (R) and without (U) a restriction of five progeny per dam.

\begin{tabular}{|c|c|c|c|c|c|c|c|c|c|c|}
\hline \multirow{2}{*}{$\begin{array}{l}\text { Inbreeding } \\
\text { constraint } \\
(\%)\end{array}$} & \multicolumn{2}{|c|}{ Ayrshire } & \multicolumn{2}{|c|}{ Brown Swiss } & \multicolumn{2}{|c|}{ Guernsey } & \multicolumn{2}{|c|}{ Holstein } & \multicolumn{2}{|c|}{ Jersey } \\
\hline & $\mathrm{U}$ & $\mathrm{R}$ & $\mathrm{U}$ & $\mathrm{R}$ & $\mathrm{U}$ & $\mathrm{R}$ & $\mathrm{U}$ & $\mathrm{R}$ & $\mathrm{U}$ & $\mathrm{R}$ \\
\hline 4 & & & & & & & 59 & 289 & 51 & 60 \\
\hline 5 & & & 25 & 25 & & & 31 & 280 & 36 & 44 \\
\hline 6 & 15 & 15 & 18 & 18 & 20 & 20 & 20 & 269 & 29 & 35 \\
\hline 7 & 15 & 15 & 12 & 12 & 20 & 20 & 15 & 263 & 21 & 31 \\
\hline 8 & 15 & 15 & 10 & 9 & 18 & 18 & 9 & 262 & 15 & 29 \\
\hline 9 & 15 & 13 & 9 & 6 & 14 & 14 & 6 & 261 & 13 & 32 \\
\hline 10 & 12 & 12 & 6 & 6 & 13 & 13 & 5 & 261 & 11 & 20 \\
\hline 11 & 11 & 10 & 6 & 7 & 12 & 11 & 3 & 261 & 10 & 28 \\
\hline 12 & 10 & 7 & 5 & 6 & 10 & 10 & 3 & 261 & 7 & 28 \\
\hline 13 & 6 & 5 & 5 & 6 & 9 & 8 & 3 & 261 & 6 & 28 \\
\hline
\end{tabular}

bull dams decreased rapidly as the inbreeding constraint was relaxed, and more bull dams were selected when a constraint was placed on their reproductive capacity, particularly for the numerically large breeds.

Table 4 shows the weighted mean age of bull sires according to the level of inbreeding constraint. Mean age of bull sires ranged from 74 mo in Jerseys to 95 mo in Ayrshires at the minimum inbreeding constraint. At the maximum inbreeding constraint, mean age of bull sires ranged from 68 mo in Jerseys to 96 mo in Brown Swiss. Mean age of bull sires decreased substantially in Ayrshires, Guernseys, Holsteins, and Jerseys as the acceptable inbreeding level increased. However, the opposite trend was found in Brown Swiss, where somewhat older bulls were chosen at the higher rates of inbreeding. Table 5 shows the weighted mean age of bull dams according to the level of inbreeding constraint. Mean age of bull dams at the minimum inbreeding constraint ranged from 52 mo in Holsteins to 84 mo in Ayrshires. At the maximum inbreeding constraint, mean age ranged from 56 mo in Holsteins (with the reproductive constraint) to $107 \mathrm{mo}$ in Brown Swiss. With the exception of the Guernsey breed, age of bull dams increased as the allowable inbreeding level in- creased, if the female reproductive rate was unconstrained. With the reproductive rate constrained, however, there was no clear trend in age of bull dams across inbreeding levels.

Table 6 shows the weighted mean inbreeding coefficient of bull sires, according to the level of inbreeding constraint. Mean inbreeding coefficients varied widely, from $1.1 \%$ in Brown Swiss sires at the $13 \%$ inbreeding constraint, to $7.5 \%$ in Jersey sires at the $11 \%$ inbreeding constraint (in both cases the female reproductive capacity was constrained). In Ayrshires, there was no clear trend in sires' inbreeding coefficients as the inbreeding constraint was modified. In Brown Swiss and Guernseys, bull sires were slightly less inbred at higher levels of the inbreeding constraint, but in Holsteins and Jerseys the trend was in the opposite direction. Restricting the female reproductive capacity did not have a consistent impact on inbreeding coefficients of bull sires.

Table 7 shows the weighted mean inbreeding coefficient of bull dams, according to the level of inbreeding constraint. Brown Swiss dams had the lowest inbreeding coefficients, $2.2 \%$, at the 12 or $13 \%$ levels of the inbreeding constraint (with reproductive capacity unconstrained). On the other hand, Jersey bull dams con-

Table 4. Weighted mean age of the selected bull sires (in months), according to the level of inbreeding constraint, with $(\mathrm{R})$ and without $(\mathrm{U})$ a restriction of five progeny per dam.

\begin{tabular}{|c|c|c|c|c|c|c|c|c|c|c|}
\hline \multirow{2}{*}{$\begin{array}{l}\text { Inbreeding } \\
\text { constraint } \\
(\%)\end{array}$} & \multicolumn{2}{|c|}{ Ayrshire } & \multicolumn{2}{|c|}{ Brown Swiss } & \multicolumn{2}{|c|}{ Guernsey } & \multicolumn{2}{|c|}{ Holstein } & \multicolumn{2}{|c|}{ Jersey } \\
\hline & $\mathrm{U}$ & $\mathrm{R}$ & $\mathrm{U}$ & $\mathrm{R}$ & $\mathrm{U}$ & $\mathrm{R}$ & $\mathrm{U}$ & $\mathrm{R}$ & $\mathrm{U}$ & $\mathrm{R}$ \\
\hline 4 & & & & & & & 84 & 88 & 74 & 74 \\
\hline 5 & & & 93 & 93 & & & 79 & 75 & 71 & 71 \\
\hline 6 & 95 & 95 & 91 & 91 & 88 & 88 & 74 & 70 & 70 & 70 \\
\hline 7 & 92 & 92 & 90 & 91 & 85 & 85 & 71 & 69 & 70 & 70 \\
\hline 8 & 89 & 89 & 90 & 93 & 82 & 82 & 70 & 69 & 69 & 70 \\
\hline 9 & 87 & 87 & 91 & 95 & 80 & 80 & 70 & 69 & 69 & 70 \\
\hline 10 & 85 & 85 & 92 & 100 & 79 & 79 & 69 & 70 & 69 & 69 \\
\hline 11 & 84 & 84 & 93 & 104 & 78 & 76 & 69 & 70 & 69 & 64 \\
\hline 12 & 84 & 84 & 94 & 109 & 76 & 73 & 69 & 71 & 68 & 64 \\
\hline 13 & 84 & 84 & 96 & 115 & 75 & 72 & 69 & 71 & 68 & 64 \\
\hline
\end{tabular}


Table 5. Weighted mean age of the selected bull dams (in months), according to the level of inbreeding constraint, with $(\mathrm{R})$ and without $(\mathrm{U})$ a restriction of five progeny per dam.

\begin{tabular}{|c|c|c|c|c|c|c|c|c|c|c|}
\hline \multirow{2}{*}{$\begin{array}{l}\text { Inbreeding } \\
\text { constraint } \\
(\%)\end{array}$} & \multicolumn{2}{|c|}{ Ayrshire } & \multicolumn{2}{|c|}{ Brown Swiss } & \multicolumn{2}{|c|}{ Guernsey } & \multicolumn{2}{|c|}{ Holstein } & \multicolumn{2}{|c|}{ Jersey } \\
\hline & $\mathrm{U}$ & $\mathrm{R}$ & $\mathrm{U}$ & $\mathrm{R}$ & $\mathrm{U}$ & $\mathrm{R}$ & $\mathrm{U}$ & $\mathrm{R}$ & $\mathrm{U}$ & $\mathrm{R}$ \\
\hline 4 & & & & & & & 52 & 56 & 56 & 56 \\
\hline 5 & & & 81 & 81 & & & 55 & 55 & 62 & 63 \\
\hline 6 & 84 & 84 & 86 & 85 & 74 & 74 & 57 & 55 & 65 & 63 \\
\hline 7 & 88 & 88 & 90 & 89 & 73 & 73 & 60 & 56 & 68 & 63 \\
\hline 8 & 90 & 90 & 95 & 93 & 72 & 72 & 62 & 56 & 68 & 64 \\
\hline 9 & 89 & 89 & 98 & 94 & 71 & 71 & 64 & 56 & 67 & 64 \\
\hline 10 & 90 & 90 & 100 & 95 & 70 & 71 & 67 & 56 & 67 & 65 \\
\hline 11 & 91 & 87 & 103 & 94 & 69 & 69 & 71 & 56 & 68 & 65 \\
\hline 12 & 92 & 83 & 105 & 91 & 68 & 69 & 73 & 56 & 69 & 67 \\
\hline 13 & 92 & 80 & 107 & 91 & 67 & 65 & 74 & 56 & 70 & 65 \\
\hline
\end{tabular}

sistently had the highest inbreeding coefficients, and these were as high as $5.8 \%$ at the maximum level of the inbreeding constraint (with reproductive capacity constrained). Raising the inbreeding constraint led to more inbred bull dams in the Guernsey, Holstein, and Jersey breeds, but this trend was not observed in the Ayrshire and Brown Swiss breeds. Constraining the female reproductive capacity did not consistently lead to selection of more or less inbred bull dams. Note that the inbreeding coefficients of selected parents are peculiar to the population structure of each breed, and we cannot make a general conclusion based on the data presented in these tables.

Table 8 shows the mean expected inbreeding coefficient of future progeny which, as measured by the USDA Animal Improvement Programs Laboratory, reflects the mean relationship of each sire to a random sample of 600 females from its respective breed. This measure is typically used to classify a given sire as "highly related to the breed" or as "an outcross." As shown in the table, relaxing the inbreeding constraint led to selection of Holstein sires that were more highly related to the breed. However, only a slight trend was observed for Jersey sires, and no trend was observed in the other three breeds. In other words, the selected sires at the maximum inbreeding constraint were no more related to the breed than the selected sires at the minimum inbreeding constraint. Although this seems counterintuitive, the main effect of the inbreeding constraint was to encourage selection of more sires, and a more uniform number of progeny from each sire, rather than to identify a few "outcross" sires that could subsequently be used heavily within the population. In general, we feel that the long-term rates of inbreeding in the major dairy breeds are more likely to depend on relationships between selected parents (i.e., sires and dams of young AI bulls), rather than relationships between available AI sires and the remainder of the population.

Table 9 shows the weighted mean Lifetime Net Merit of the selected group (bull sires and bull dams combined), according to the level of inbreeding constraint. Results are not comparable across breeds, because PTA for each breed are expressed relative to a different genetic base. In Holsteins, for example, mean Lifetime Net Merit increased from $\$ 573$ at $4 \%$ inbreeding to $\$ 794$ at $13 \%$ inbreeding. The corresponding increase in Jerseys was from $\$ 413$ to $\$ 615$. This demonstrates that

Table 6. Weighted mean inbreeding level of the selected bull sires, according to the level of inbreeding constraint, with $(\mathrm{R})$ and without $(\mathrm{U})$ a restriction of five progeny per dam.

\begin{tabular}{|c|c|c|c|c|c|c|c|c|c|c|}
\hline \multirow{2}{*}{$\begin{array}{l}\text { Inbreeding } \\
\text { constraint } \\
\text { (\%) }\end{array}$} & \multicolumn{2}{|c|}{ Ayrshire } & \multicolumn{2}{|c|}{ Brown Swiss } & \multicolumn{2}{|c|}{ Guernsey } & \multicolumn{2}{|c|}{ Holstein } & \multicolumn{2}{|c|}{ Jersey } \\
\hline & $\mathrm{U}$ & $\mathrm{R}$ & $\mathrm{U}$ & $\mathrm{R}$ & $\mathrm{U}$ & $\mathrm{R}$ & $\mathrm{U}$ & $\mathrm{R}$ & $\mathrm{U}$ & $\mathrm{R}$ \\
\hline 4 & & & & & & & 4.1 & 3.9 & 6.0 & 5.9 \\
\hline 5 & & & 3.3 & 3.3 & & & 4.4 & 4.6 & 6.1 & 6.1 \\
\hline 6 & 5.5 & 5.5 & 3.3 & 3.3 & 3.8 & 3.8 & 4.5 & 4.6 & 6.1 & 6.1 \\
\hline 7 & 5.6 & 5.6 & 3.3 & 3.2 & 3.9 & 3.9 & 4.6 & 4.7 & 6.1 & 6.2 \\
\hline 8 & 5.8 & 5.8 & 3.1 & 3.0 & 4.0 & 4.0 & 4.6 & 4.6 & 6.1 & 6.4 \\
\hline 9 & 5.9 & 5.9 & 3.1 & 2.6 & 4.0 & 4.0 & 4.7 & 4.6 & 6.2 & 6.9 \\
\hline 10 & 5.9 & 5.9 & 2.9 & 2.2 & 3.7 & 3.6 & 4.8 & 4.6 & 6.3 & 7.2 \\
\hline 11 & 5.9 & 5.8 & 2.8 & 2.0 & 3.4 & 3.1 & 4.7 & 4.7 & 6.4 & 7.5 \\
\hline 12 & 5.7 & 5.6 & 2.8 & 1.7 & 3.2 & 2.7 & 4.6 & 4.8 & 6.5 & 6.9 \\
\hline 13 & 5.6 & 5.4 & 2.7 & 1.1 & 2.9 & 2.5 & 4.5 & 4.8 & 6.7 & 6.5 \\
\hline
\end{tabular}


Table 7. Weighted mean inbreeding level of the selected bull dams, according to the level of inbreeding constraint, with $(\mathrm{R})$ and without $(\mathrm{U})$ a restriction of five progeny per dam.

\begin{tabular}{|c|c|c|c|c|c|c|c|c|c|c|}
\hline \multirow{2}{*}{$\begin{array}{l}\text { Inbreeding } \\
\text { constraint } \\
\text { (\%) }\end{array}$} & \multicolumn{2}{|c|}{ Ayrshire } & \multicolumn{2}{|c|}{ Brown Swiss } & \multicolumn{2}{|c|}{ Guernsey } & \multicolumn{2}{|c|}{ Holstein } & \multicolumn{2}{|c|}{ Jersey } \\
\hline & $\mathrm{U}$ & $\mathrm{R}$ & $\mathrm{U}$ & $\mathrm{R}$ & $\mathrm{U}$ & $\mathrm{R}$ & $\mathrm{U}$ & $\mathrm{R}$ & $\mathrm{U}$ & $\mathrm{R}$ \\
\hline 4 & & & & & & & 3.9 & 3.9 & 5.3 & 5.3 \\
\hline 5 & & & 3.0 & 3.0 & & & 4.0 & 3.9 & 5.0 & 5.2 \\
\hline 6 & 4.2 & 4.2 & 2.6 & 2.6 & 3.3 & 3.3 & 4.1 & 4.2 & 5.0 & 5.2 \\
\hline 7 & 4.0 & 4.0 & 2.5 & 2.5 & 3.7 & 3.7 & 4.0 & 4.3 & 5.1 & 5.6 \\
\hline 8 & 3.8 & 3.8 & 2.4 & 2.6 & 3.8 & 3.8 & 4.2 & 4.3 & 5.2 & 5.6 \\
\hline 9 & 3.8 & 3.8 & 2.4 & 2.6 & 3.9 & 3.7 & 4.4 & 4.3 & 5.3 & 5.5 \\
\hline 10 & 3.7 & 3.7 & 2.3 & 2.6 & 3.9 & 3.7 & 4.4 & 4.4 & 5.4 & 5.6 \\
\hline 11 & 3.7 & 3.9 & 2.3 & 2.7 & 3.9 & 3.8 & 4.4 & 4.4 & 5.4 & 5.7 \\
\hline 12 & 3.6 & 4.1 & 2.2 & 2.8 & 4.0 & 3.8 & 4.4 & 4.4 & 5.4 & 5.7 \\
\hline 13 & 3.5 & 4.2 & 2.2 & 2.8 & 4.1 & 4.0 & 4.4 & 4.4 & 5.4 & 5.8 \\
\hline
\end{tabular}

there can be a significant cost in controlling inbreeding; the average genetic merit of the selected group will always be higher if we ignore inbreeding. As expected, however, the cost of controlling inbreeding is not linear. Large sacrifices in genetic merit may be necessary to achieve extremely low levels of inbreeding, but a moderate reduction in inbreeding is less costly. For example, the difference in genetic merit of Holstein bull parents at $4 \%$ inbreeding versus $8 \%$ inbreeding was $\$ 182$ (with no female reproductive constraint), but the corresponding difference between Holstein bull parents at 9\% inbreeding versus $13 \%$ inbreeding was only $\$ 25$. Thus, it appears that the cost of controlling inbreeding will be manageable. Mean genetic merit was typically lower when a constraint was placed on female reproductive capacity, because more bull dams were needed (hence lower selection intensity).

Table 10 shows the weighted mean Lifetime Net Merit of the selected group, after adjustment to zero inbreeding using a cost factor of $\$ 23$ per $1 \%$ inbreeding (Smith et al., 1998). As shown in the table, the optimal level of inbreeding in the next generation appears to be intermediate for all five breeds. Without a constraint on female reproductive capacity, adjusted genetic merit was maximized at 8\% inbreeding in Ayrshires and 7\% in Brown Swiss, Guernseys, Holsteins, and Jerseys. When female reproductive capacity was limited, this function was maximized at 8\% in Ayrshires, $7 \%$ in Brown Swiss and Guernseys, and 6\% in Holsteins and Jerseys. In general, selection for net lifetime profit adjusted for inbreeding depression seems to be an appropriate strategy, because it implies that higher rates of inbreeding are acceptable if the costs of inbreeding depression are small or if the costs of inbreeding depression are (more than) offset by economic returns from genetic progress.

\section{CONCLUSIONS}

In summary, the use of optimal contribution methodology to control relationships between young AI bulls while simultaneously maximizing genetic merit appears promising. A slight sacrifice in genetic gain may be required to achieve a desirable rate of accumulation of inbreeding, but this sacrifice should not be problematic unless severe constraints on inbreeding are imposed. If genetic gains are standardized to a common level of inbreeding, it is clear that balancing inbreeding

Table 8. Weighted mean expected future inbreeding of progeny of the selected bull sires, according to the level of inbreeding constraint, with (R) and without (U) a restriction of five progeny per dam.

\begin{tabular}{|c|c|c|c|c|c|c|c|c|c|c|}
\hline \multirow{2}{*}{$\begin{array}{l}\text { Inbreeding } \\
\text { constraint } \\
(\%)\end{array}$} & \multicolumn{2}{|c|}{ Ayrshire } & \multicolumn{2}{|c|}{ Brown Swiss } & \multicolumn{2}{|c|}{ Guernsey } & \multicolumn{2}{|c|}{ Holstein } & \multicolumn{2}{|c|}{ Jersey } \\
\hline & $\mathrm{U}$ & $\mathrm{R}$ & $\mathrm{U}$ & $\mathrm{R}$ & $\mathrm{U}$ & $\mathrm{R}$ & $\mathrm{U}$ & $\mathrm{R}$ & $\mathrm{U}$ & $\mathrm{R}$ \\
\hline 4 & & & & & & & 4.4 & 4.3 & 7.2 & 7.2 \\
\hline 5 & & & 5.7 & 5.7 & & & 4.6 & 4.7 & 7.3 & 7.3 \\
\hline 6 & 6.2 & 6.2 & 5.8 & 5.8 & 5.7 & 5.7 & 4.7 & 4.9 & 7.3 & 7.3 \\
\hline 7 & 6.2 & 6.2 & 5.9 & 5.9 & 5.6 & 5.6 & 4.8 & 5.0 & 7.3 & 7.3 \\
\hline 8 & 6.2 & 6.2 & 5.9 & 5.9 & 5.5 & 5.5 & 4.9 & 5.0 & 7.3 & 7.4 \\
\hline 9 & 6.2 & 6.2 & 5.9 & 5.9 & 5.5 & 5.5 & 4.9 & 5.1 & 7.3 & 7.5 \\
\hline 10 & 6.2 & 6.2 & 5.9 & 5.8 & 5.5 & 5.5 & 5.0 & 5.1 & 7.3 & 7.6 \\
\hline 11 & 6.2 & 6.2 & 5.9 & 5.7 & 5.5 & 5.4 & 5.0 & 5.0 & 7.3 & 7.7 \\
\hline 12 & 6.1 & 6.1 & 5.9 & 5.7 & 5.4 & 5.4 & 5.0 & 5.0 & 7.4 & 7.6 \\
\hline 13 & 6.1 & 6.0 & 5.8 & 5.7 & 5.4 & 5.4 & 5.1 & 5.0 & 7.4 & 7.5 \\
\hline
\end{tabular}


Table 9. Weighted mean Lifetime Net Merit (in dollars) of the selected group, according to the level of inbreeding constraint, with $(\mathrm{R})$ and without (U) a restriction of five progeny per dam (results are not comparable across breeds).

\begin{tabular}{|c|c|c|c|c|c|c|c|c|c|c|}
\hline \multirow{2}{*}{$\begin{array}{l}\text { Inbreeding } \\
\text { constraint } \\
(\%)\end{array}$} & \multicolumn{2}{|c|}{ Ayrshire } & \multicolumn{2}{|c|}{ Brown Swiss } & \multicolumn{2}{|c|}{ Guernsey } & \multicolumn{2}{|c|}{ Holstein } & \multicolumn{2}{|c|}{ Jersey } \\
\hline & $\mathrm{U}$ & $\mathrm{R}$ & $\mathrm{U}$ & $\mathrm{R}$ & $\mathrm{U}$ & $\mathrm{R}$ & $\mathrm{U}$ & $\mathrm{R}$ & $\mathrm{U}$ & $\mathrm{R}$ \\
\hline 4 & & & & & & & 573 & 485 & 413 & 408 \\
\hline 5 & & & 532 & 532 & & & 653 & 569 & 475 & 470 \\
\hline 6 & 373 & 373 & 587 & 587 & 377 & 377 & 701 & 599 & 512 & 504 \\
\hline 7 & 419 & 419 & 620 & 618 & 411 & 411 & 733 & 611 & 538 & 525 \\
\hline 8 & 448 & 448 & 641 & 635 & 432 & 432 & 755 & 616 & 559 & 538 \\
\hline 9 & 470 & 470 & 656 & 646 & 445 & 445 & 769 & 619 & 575 & 546 \\
\hline 10 & 486 & 486 & 669 & 654 & 454 & 453 & 780 & 621 & 588 & 551 \\
\hline 11 & 499 & 498 & 679 & 659 & 460 & 458 & 786 & 621 & 599 & 555 \\
\hline 12 & 509 & 508 & 688 & 663 & 466 & 462 & 791 & 622 & 607 & 556 \\
\hline 13 & 518 & 515 & 696 & 667 & 470 & 464 & 794 & 622 & 615 & 557 \\
\hline
\end{tabular}

and selection is an economically viable exercise. Achieving such a balance will not require the identification of a few "outcross" sires for future use in the population. Instead, it will necessitate the use of a greater number of sires and dams, and it will require a more uniform number of progeny from each. In addition, slightly older animals may be chosen as parents. Constraints on the female reproductive capacity will be necessary due to biological limitations of potential dams, but such constraints should be used cautiously, because they can substantially alter the results. In the presence of inbreeding constraints, selection of sires and dams must be done simultaneously, because the usefulness of any individual sire or dam depends critically on its relationship to the sires and dams that have already been chosen. Conceptually this is not a problem, but bias in PTA of elite cows due to preferential treatment could lead to the overuse of certain cows (and perhaps the selection of too many bulls), unless the female reproductive rate is tightly constrained. Although optimal contribution methodology seems to provide a useful framework for balancing selection and inbreeding, implementation in a dispersed population will clearly be more challenging than prior applications in closed nucleus populations. Cooperation between breed associations, pedigree breeders, and competing AI organizations will be necessary to ensure that a diverse group of young sires is sampled, and to ensure that individual families are not overused. Based on discussions with key industry leaders, it appears that such cooperate may be possible, particularly for the 'colored' breeds. Our intention is to focus on the Jersey breed first, because inbreeding is increasing most rapidly in this breed, and because pedigree breeders, sire analysts, and breed association staff have expressed interest in such a program. Future work should focus on determination of the optimal rate of accumulation of inbreeding, accommodation of overlapping generations, and characterization of the total cost of inbreeding effects on fertility, production, health, and survival. In practice, applications of this methodology will also need to consider the genetic composition of heifers, calves, and pregnancies (i.e., recent matings), because although these animals are not yet selection candidates, they may be highly related to certain bull

Table 10. Weighted mean adjusted Lifetime Net Merit (in dollars) of the selected group, according to the level of inbreeding constraint, with $(\mathrm{R})$ and without $(\mathrm{U})$ a restriction of five progeny per dam (results are not comparable across breeds). Results are adjusted to zero inbreeding using a cost factor of $\$ 23.00$ in Lifetime Net Merit per $1 \%$ inbreeding.

\begin{tabular}{|c|c|c|c|c|c|c|c|c|c|c|}
\hline \multirow{2}{*}{$\begin{array}{l}\text { Inbreeding } \\
\text { constraint } \\
(\%)\end{array}$} & \multicolumn{2}{|c|}{ Ayrshire } & \multicolumn{2}{|c|}{ Brown Swiss } & \multicolumn{2}{|c|}{ Guernsey } & \multicolumn{2}{|c|}{ Holstein } & \multicolumn{2}{|c|}{ Jersey } \\
\hline & $\mathrm{U}$ & $\mathrm{R}$ & $\mathrm{U}$ & $\mathrm{R}$ & $\mathrm{U}$ & $\mathrm{R}$ & $\mathrm{U}$ & $\mathrm{R}$ & $\mathrm{U}$ & $\mathrm{R}$ \\
\hline 4 & & & & & & & 481 & 393 & 321 & 316 \\
\hline 5 & & & 417 & 417 & & & 538 & 454 & 360 & 355 \\
\hline 6 & 235 & 235 & 449 & 449 & 239 & 239 & 563 & 461 & 374 & 366 \\
\hline 7 & 258 & 258 & 459 & 457 & 250 & 250 & 572 & 450 & 377 & 364 \\
\hline 8 & 264 & 264 & 457 & 451 & 248 & 248 & 571 & 432 & 375 & 354 \\
\hline 9 & 263 & 263 & 449 & 439 & 238 & 238 & 562 & 412 & 368 & 339 \\
\hline 10 & 256 & 256 & 439 & 424 & 224 & 223 & 550 & 391 & 358 & 321 \\
\hline 11 & 246 & 245 & 426 & 406 & 207 & 205 & 533 & 368 & 346 & 302 \\
\hline 12 & 233 & 232 & 412 & 387 & 190 & 186 & 515 & 346 & 331 & 280 \\
\hline 13 & 219 & 216 & 397 & 368 & 171 & 165 & 495 & 323 & 316 & 258 \\
\hline
\end{tabular}


sires or dams. Given the availability of optimal contribution methodology for controlling relationships between young AI bulls, as well as the widespread use of computerized mating programs for controlling inbreeding on the farm, future prospects for achieving a suitable balance between selection and inbreeding seem positive.

\section{ACKNOWLEDGMENTS}

Financial support for this study was provided by the National Association of Animal Breeders, Columbia, Missouri, and the Babcock Institute for International Dairy Research and Development, Madison, Wisconsin.

\section{REFERENCES}

Brisbane, J. R., and J. P. Gibson. 1995. Balancing selection response and rate of inbreeding by including genetic relationships in selection decisions. Theor. Appl. Genet. 91:421-431.

Grundy, B., B. Villaneuva, and J. A. Woolliams. 1998. Dynamic selection procedures for constrained inbreeding and their consequences for pedigree development. Genet. Res. Cambridge 72:159-168.
Grundy, B., B. Villaneuva, and J. A. Woolliams. 2000. Dynamic selection for maximizing response with constrained inbreeding in schemes with overlapping generations. Anim. Sci. 70:373-382.

Meuwissen, T. H. E. 1997. Maximizing the response of selection with a predefined rate of inbreeding. J. Anim. Sci. 75:934-940.

Meuwissen, T. H. E., and M. E. Goddard. 1997. Optimization of progeny tests with prior information on young bulls. Livest. Prod. Sci. 52:57-68.

Meuwissen, T. H. E., and A. K. Sonesson. 1998. Maximizing the response of selection with a predefined rate of inbreeding: overlapping generations. J. Anim. Sci. 76:2575-2583.

Smith, L. A., B. G. Cassell, and R. E. Pearson. 1998. The effects of inbreeding on the lifetime performance of dairy cattle. J. Dairy Sci. 81:2729-2737.

Sonesson, A. K., B. Grundy, J. A. Woolliams, and T. H. E. Meuwissen. 2000. Selection with control of inbreeding in populations with overlapping generations: a comparison of methods. Anim. Sci. $70: 1-8$.

Weigel, K. A. 2001. Controlling inbreeding in modern breeding programs. J. Dairy Sci. 84(E. Suppl.):E177-E184.

Weigel, K. A., and S. W. Lin. 2000. Use of computerized mate selection programs to control inbreeding of Holstein and Jersey cattle in the next generation. J. Dairy Sci. 83:822-828.

Wilk, J. C., and B. T. McDaniel. 1995. Influence of genetic diversity on viability in Randleigh Jerseys. J. Dairy Sci. 78(Suppl. 1):154. (Abstr.)

Woolliams, J. A., and T. H. E. Meuwissen. 1993. Decision rules and variance of response in breeding schemes. Anim. Prod. 56:179186.

Wray, N. R., and M. E. Goddard. 1994. Increasing long-term response to selection. Genet. Sel. Evol. 26:431-451. 